\title{
Squatting on Government Land
}

\author{
by \\ Nilopa Shah* \\ Department of Economics \\ University of California, Irvine \\ 3151 Social Science Plaza Irvine, CA 92697 \\ email: nilopa.shah@uci.edu
}

February 20, 2013

\begin{abstract}
This paper presents an economic theory of squatter settlements in developing countries. It adds to the existing literature by explicitly modeling squatting on government-owned land and presents a unified framework for analysis of issues related to squatting, urban planning and policy. In the model, a squatter-organizer optimally controls squatting so as to forestall eviction. The model highlights how the existence of an eviction cost leads to formal residents tolerating squatting, trading-off 'open space' to avoid paying taxes toward evicting squatters. The paper derives comparative-static results under some functional form assumptions. The analysis is extended to examine the comparative-static effects for the case where squatters freely migrate into the city. The framework for exploring a combined model of squatting on government and private land is also laid out. Lastly, some policy analysis of squatter formalization is carried out.
\end{abstract}

KeyWords: Developing Countries, Urban Economics, Squatter Settlements

*I am deeply grateful to my advisor, Jan Brueckner, for his constant help, support and encouragement and careful edits; to Manisha Shah and Priya Ranjan for constructive comments on early drafts; and to Ken Small for help with reviewing the literature. I would like to thank the audience of my presentation at the AEA (2012) meetings as well as the wonderful participants, including my referee, Jenny Schuetz, at the USC Rusk School Annual Research Symposium on Global Cities for a very insightful critique of my work. I would also like to thank Yves Zenou and three unknown referees for their constructive suggestions for revising the paper. 


\section{Introduction}

Vast numbers of urban residents around the world live in slums. According to the latest UN Habitat Report (2009), about 1 billion people, or 32 percent of the world's current urban population, are slum-dwellers. This percentage is higher, at 37 percent, for the group of less developed countries. The slum share is 43 percent in South Asia and 36 percent in East Asia, and it reaches a high of 62 percent in sub-Saharan Africa. Urban slums in developing countries are often associated with informal land tenure. Informality usually involves squatting, where households illegally occupy a parcel of land while paying no compensation to its owner. Although a separate tabulation of the worldwide squatter population is not available, case studies suggest that a substantial share of slum residents, and thus a substantial share of the urban population in developing countries, consists of squatters. For example, in the city of Dhaka, Bangladesh squatter settlements are estimated to provide as much as 15 percent of the housing stock (World Bank 2007).

An understanding of slums in developing countries thus goes hand in hand with an understanding of squatting. Along with other social scientists, economists have expended some effort studying the squatting phenomenon, leading to a literature of modest size. This literature contains some theoretical contributions along with a few empirical contributions, which rely on scarce data to explore various aspects of squatter settlements. So far, theoretical work has presented models of squatting on privately-owned land (Hoy and Jimenez (1991), Turnbull (2008), Brueckner and Selod (2009)). Each of these papers analyzes the incentives for eviction of squatters and portrays private landowners as balancing the cost of evicting squatters and the gains from earning private rent after eviction. This balancing results in an equilibrium level of squatting and rate of eviction in a particular city. Although this literature clarifies eviction incentives when squatting occurs on private land, it does not shed light on the treatment of squatters occupying public land. This paper aims to add to the existing theoretical literature by presenting a model of squatting on public land. 
A significant proportion of squatting in developing countries occurs on vacant government-owned land (Laquain 1972). According to Flood (2006), 49 per cent of land invasions in Sub-Saharan Africa, 60 per cent in North Africa, East Asia and West Asia and 90 per cent in South Asia occur on public land. ${ }^{1}$ Of the 20 slum communities surveyed by Lanjouw and Levy (2002) in urban Ecuador, 12 occupied public land.

Society obtains value from whatever use government land would be put to in the absence of squatting. This value is lost when squatters occupy it. ${ }^{2}$ The loss from squatter occupation of the land could involve forsaken benefits from blocked infrastructure projects, such as enlargement of an airport ringed by squatter settlements (Mumbai, India represents such a case), or forgone revenue from sale of the land to the private sector for residential, commercial or industrial development. If this loss is big enough, eviction of the squatters by the government would presumably occur. To analyze the government's incentives, a model must describe how the social value of government land is determined. The model presented in this paper uses a simple stylized framework in which the city's vacant government land is used for public recreation and referred to as 'open space' that provides utility to formal sector residents. In the model, 'open space' is a metaphor for more general uses of government-owned land, designed to enhance the well-being of the formal residents.

The model's open space could, alternatively, consist of land areas considered marginal, such as rights-of-way of highways and railways, or marshes, flood plains, ravines and hillsides, which are under government jurisdiction. This possibility suggests that the valuation of government land by formal residents could depend on its use and topography. Accounting for these alternative uses of would require a more detailed framework than the set-up presented here. But the spirit of the story would remain the same.

A part of this open space is occupied by 'squatters,' who constitute the city's informal residents and who use the vacant land without paying rent for it. The government may allow such a land 'invasion' because eviction (and resettlement) of squatters might not be worth the cost incurred, with the formal residents better-off tolerating some level 
of squatting. The government's rationale is understood by the 'squatter-organizer,' a community leader who governs the squatter settlements in the city so as to not elicit eviction. There is ample anecdotal evidence of slum populations being led by a community leader. Such squatter-organizers are known by different names around the world. For example, they are called community bosses in Ecuador, shack lords in South Africa, mastaans in Bangladesh and pradhans in India. The study on Dhaka (World Bank 2007) noted that mastaans "are self appointed leaders who set up committees, maintain links and have patronage from local and national political leaders, government officials and local law enforcing agencies." An ethnographic survey by Jha, Rao, and Woolcock (2007) of 800 households across 4 slums in Delhi, India highlights the functioning of informal governance systems in these slums, headed by pradhans, whose primary role is to serve as intermediaries between slum residents and formal government and mitigate the risk of demolition. In the Ecuador study by Lanjouw and Levy (2002), 9 of 20 communities included in the survey were managed by a community boss, who collected 'rent' from the households residing in the community. Further, 83 percent of residents interviewed in communities with a community boss perceived eviction as impossible, while this figure was only 58 percent for respondents from communities without a community boss. These figures indicate that a perception of higher tenure security is associated with the presence of an organizer, validating a central aspect of the model.

The squatter organizer dictates a level of defensive expenditures by each squatter household, which help to protect tenure on the land they occupy. The expenditures could be used for political lobbying or 'bribes' to politicians intended to build support for the squatter community, making eviction more difficult politically. Or the expenditures could be direct payments to a squatter security force or 'guards, protecting the settlement from eviction. Alternatively, these expeditures could be viewed as representing forgone labor income as squatters spend time at home defending their plots rather than working at full capacity (Field 2007). The level of defensive expenditures, along with the size of the squatter population, determine the level of 'eviction cost' that would be borne by the 
government in order to evict the squatters and free more open space. This eviction cost is paid in the form of a head tax by the city's formal residents. The tax represents the sacrifice required to reclaim the open space occupied by the squatters, and if the sacrifice is worthwhile, eviction occurs.

The land area of the squatter settlement, which determines the loss of open space due to squatting, depends on both the squatter population and the size of individual plots, both of which are under the control of the organizer. By setting the levels of these variables as well as defensive expenditures in proper fashion, the organizer is able to deter eviction entirely (ensuring that the formal head tax is not worth paying) while maximizing the squatter utility level. Thus, the paper presents a model of government and squatter-organizer interactions that give rise to a squatting equilibrium.

The idea of a squatter-organizer as a centralized decision-maker for the squatter community was first introduced in Brueckner and Selod (2009) [henceforth BS], and the present framework shares a number of features of their model. As in the current model, the squatter organizer in BS dictates defensive expenditures and controls the squatter population $^{3}$ and plot sizes, and his goal is to maximize squatter utility. However, since squatting occurs on private land in BS and on government land in the present model, the eviction condition is crucially different in the two models. Eviction in BS is carried out by private landowners in response to market incentives, recognizing that eviction allows the cleared land to be rented out in the city's formal housing market. If the formal land price exceeds eviction costs (which are expressed on a per-unit-of-land basis in BS), then the plot's landowner gains by evicting the squatter and renting the land in the formal market. Therefore, to prevent eviction, the organizer must set his choice variables to keep eviction costs above the formal price.

But since the city's land area is fixed, with squatters and formal residents competing for the same land, the organizer's choices in BS also affect the formal price through a process of "squeezing," under which a larger squatter land area cuts the supply of land to the formal market and thus raises the formal price. The squatter organizer's decisions 
in BS thus affect both elements in the private landowner's "eviction condition," eviction costs and the formal land price. In the current framework, by contrast, the agent carrying out evictions is not a private landowner, but is instead the government, acting on the behalf of formal residents. The eviction condition requires the organizer to limit the utility loss from the reduction of open space, keeping it less than the loss from incurring eviction costs. Note that in BS, no decision maker considers the welfare of formal households, although their well-being is affected indirectly by the squeezing process, which determines the level of the formal price. Thus, while the models have much in common, the critical eviction component is quite different.

In contrast to BS and the present paper, early economic research on squatting began by addressing the question of why households choose to squat. Jimenez (1985) presented a model of squatting as a utility-maximizing tenure choice made by households under price and income uncertainity. Around the same time, hedonic price estimations using data from cities in the Philippines (Jimenez (1984), Friedman, Jimenez, and Mayo (1988)) found significant premia associated with tenure security, as reflected in a difference in unit housing prices between the formal housing sector of a city and its informal squatting sector. $^{4}$

Later, the focus of the literature on squatting shifted to modeling strategic interactions between landowners and squatters under uncertainity about the potential development values of land parcels. Such models (Hoy and Jimenez (1991), Turnbull (2008)) analyzed the squatting equilibrium arising out of landowners' eviction decisions and squatters' housing-capital investment decisions. These models pointed towards excessive (higher than socially optimal) evictions by landowners.

In contrast to these decentralized models, no eviction occurs in equilibrium in either the BS model or the current set-up, though the threat of eviction is present. While no (or very low) rates of eviction ${ }^{5}$ and the existence of some form of community leadership match real-world evidence, the BS model provides an incomplete picture by ignoring the phenomenon of squatting on government land, which is important in reality. Hence, this 
paper borrows elements from BS to develop a model that covers this important case. Later on, the paper shows how to combine both models in a unified framework that has squatting on both private and public land.

The paper is organized in the following manner. First, the basic model of how squatting on government land arises is presented. For tractability of results, some functional form assumptions are imposed on the formal-resident and squatter utility functions. These assumptions in turn imply restrictions on the form of the eviction-cost function, which is crucial to characterizing the squatting equilibrium. Further, a comparative-static analysis is carried out to show how the choice variables are affected by the model's parameters. This discussion is followed by an analysis of the free-migration case, where squatter migration into the city is uncontrollable and, hence, the squatter-organizer cannot control the size of the squatter population. Next, a combined model of squatting on private and government land is explored. Finally, an attempt is made to present some policy analysis of possible Pareto-improving government interventions. This later analysis has the potential to facilitate public policy discussions regarding squatter formalization.

Like the BS model, the present model generates some comparative-static predictions about the effects of parameter changes on the squatter equilibrium. Despite the use of different functional forms for preferences, some results are common to the two models, but others are different. For example, an increase in the formal population in both models increases the equilibrium size of the squatter population while reducing their plot sizes, and an increase in the squatter-utility weight on land raises defensive expenditures. But some parameter effects present in the current model are entirely absent in the BS model. It should be noted, though, that the main contribution of this paper is not the particular results derived, but rather the presentation of a conceptual framework for the analysis of squatting on government land, which serves to fill a serious gap in the literature. 


\section{Basic Model}

The analysis relies on a stylized, static model of a city with a fixed land area. Part of the land in the city is owned by private landowners, and rented to formal residents. The rest is owned by local government. The privately-owned land area developed for formal housing is fixed at $L_{P}$. While part of the government-owned land is used for public utility needs, a fixed area $\overline{L_{G}}$ is kept vacant as open space, which provides utility to the city's formal residents.

The BS paper focused on the privately-owned land area $L_{P}$. It presented a model in which interactions between the landowners and the squatter-organizer lead part of the privately-owned land to be occupied by squatters, which squeezes the formal residents into a smaller area. This land supply reduction in turn raises the unit price of formal housing. The current paper's focus is the land area $\overline{L_{G}}$ earmarked as public open space in the city. It models local government/squatter-organizer interactions, which result in a part of the open space being usurped for squatting, while the private land area is untouched. Section 4 of the paper outlines a combined model, where squatting occurs on both private and government land.

\subsection{General Set-up}

Consider the city's open space $\bar{L}_{G}$. The squatters group, whose size is $N_{s}$, illegally occupies a part of this open space in that they do not pay rent for use of the land they occupy. In return, they face a threat of eviction from the government. To protect themselves from being evicted, squatters combat the threat of eviction as part of a squatting community governed by the squatter-organizer. The organizer collects an amount $A$ from the income $y_{s}$ of the squatters to be used in defensive expenditures, which raise the cost of eviction.

The cost of eviction is the cost that the government would have to incur to remove squatters from its land. This cost can be viewed simply as the cost of using bulldozers 
to erase squatter occupation from a plot of land or, more elaborately, to include the cost of relocating the squatters. Eviction cost is an increasing function of the defensive expenditure $A$ per household. Also, since the opposition to eviction is more forceful the larger the size of the squatter population, eviction cost rises with $N_{s}$, holding $A$ fixed. Thus, the cost of evicting $N_{s}$ squatters is expressed as $e\left(A, N_{s}\right)$.

Note that BS modeled eviction cost (borne in their model by the private landowners) on a per-unit-of-land basis, so that $E\left(A, N_{s}\right)$ in their model gives the cost of squatter removal for each unit of land occupied. In the current set-up, it is analytically more convenient to use the total eviction-cost function $e\left(A, N_{s}\right)$. Thus, the treatment of eviction cost in the two models is not equivalent. ${ }^{6}$

The objective of the squatter-organizer, who is the centralized decision-maker for the squatter community, is to maximize the utility of a representative squatter: ${ }^{7}$

$$
u_{s}\left(y_{s}-A, q_{s}\right)
$$

In (1), $y_{s}-A$ is the disposable income left over for consumption expenditures after allotting $A$ towards defensive expenditures, and $q_{s}$ is the plot size each squatter household occupies. Note that no land rent is paid. The organizer's choice variables, along with defensive expenditures $A$, includes plot size $q_{s}$, which is dictated to each squatter household. For the basic set-up, in a structure similar to a closed-city urban model, the organizer can also control the size $N_{s}$ of the squatter population. Later in the paper, this assumption will be relaxed so that squatter migration into the city is uncontrollable, which leads to the free-migration version of the model.

The city is also inhabited by a fixed number $N_{f}$ of homogenous formal residents. ${ }^{8}$ As in the BS model, formal residents derive utility from consumption and formal housing. However, the formal plot size is assumed to be exogenously fixed, so that argument is dropped from the formal utility function. It will be reintroduced later in the paper when the combined model is discussed. 
The principal innovation of the current paper is the introduction of open space as utility-enhancing for the formal residents. In order to enjoy the benefits of all the available open public space, formal residents have to bear the cost of evicting the squatters. This cost is borne in the form of a head tax paid to the government by each formal resident to defray the eviction cost. Alternatively, the formal residents could avoid paying the eviction cost by tolerating squatters and enjoying only the left-over open space. Eviction is assumed to be all-or-nothing, with either all or none of the squatters being evicted.

With squatters occupying $N_{s} q_{s}$ worth of open space, the utility of a representative formal resident can be expressed as $u_{f}\left(y_{f}, \overline{L_{G}}-N_{s} q_{s}\right)$, where $y_{f}$ is the formal disposable income after rent payments. This net income is equal to $\widetilde{y_{f}}-p_{f} q_{f}$, where $\widetilde{y_{f}}$ is the actual formal income, $p_{f}$ is the price per unit of formal housing and $q_{f}$ is the housing (land) consumption of the formal resident. Each of these variables is assumed to be exogenously fixed in the current set-up. The exogeneity assumptions on $p_{f}$ and $q_{f}$ will be relaxed later in the paper when the combined model is discussed. The second argument in the expression is the open space available to the formal residents in the presence of squatters.

Alternatively, if formal residents choose to not tolerate squatting, then they can enjoy the maximum possible open space in the city, $\overline{L_{G}}$. However, for that outcome to occur, they must pay eviction cost in the form of a head tax. In this case, representative formal resident utility can be expressed as $u_{f}\left(y_{f}-e\left(A, N_{s}\right) / N_{f}, \overline{L_{G}}\right) .{ }^{9}$

The government acts as a centralized decision-maker representing the interests of the city's formal residents. It tolerates squatting as long as the loss in utility from reduced open space due to squatting for a representative formal resident is lower than the loss in utility from reduced income due to taxes paid for evicting squatters. Thus, the government does not evict squatters as long as

$$
u_{f}\left(y_{f}, \bar{L}_{G}-N_{s} q_{s}\right) \geq u_{f}\left(y_{f}-\frac{e\left(A, N_{s}\right)}{N_{f}}, \bar{L}_{G}\right) .
$$

Equation (2) is the 'no-eviction' constraint, subject to which the squatter-organizer 
aims to maximize squatter utility (1). The constraint requires that formal residents find the use of some open space by squatters to be more attractive than bearing a share of the cost of eviction. Contrast this with the no-eviction constraint in the BS model of squatting on private land $p_{f} \leq E\left(A, N_{s}\right)$. This constraint requires the eviction cost perunit-of-land to be greater than the unit rent $p_{f}$ that can be earned following eviction, a condition which ensures that landowners find eviction unattractive.

Now that a complete description of both sides of the squatter-organizer/government interaction has been given, an analysis of squatting on government land can be carried out. The Lagrangian for the squatter-organizer's problem is

$$
L=u_{s}\left(y_{s}-A, q_{s}\right)+\lambda\left[u_{f}\left(y_{f}, \bar{L}_{G}-N_{s} q_{s}\right)-u_{f}\left(y_{f}-\frac{e\left(A, N_{s}\right)}{N_{f}}, \bar{L}_{G}\right)\right]
$$

To solve this problem, note first that the no-eviction constraint will be binding at the solution. To see this fact, suppose that the left-hand-side of (2) were greater than the right-hand-side at the optimum. In this situation, $q_{s}$ could be increased without violating the constraint, thus raising squatter utility. This contradiction means that constraint (2) must hold as an equality at the solution to the problem. In practice, this means that the organizer will expand squatter occupation until formal residents are indifferent between tolerating squatting and paying the eviction cost to enjoy more open space.

The first-order conditions for the maximization problem are presented in Appendix A.1. ${ }^{10}$ Let $u_{s c}$ and $u_{s q}$ denote the marginal utilities of consumption and plot size, respectively, for squatters; $u_{f c}$ and $u_{f q}$ denote the marginal utilities of consumption and open space, respectively, for formal residents; and $e_{A}$ and $e_{N s}$ denote the marginal eviction-cost benefits of defensive expenditures and number of squatters, respectively. Then, the first two appendix conditions, (44) and (45), jointly imply

$$
\frac{u_{s q}}{u_{s c}}=\frac{N_{f} u_{f q}}{u_{f c}} \frac{N_{s}}{e_{A}}
$$

The condition in (4) provides a joint choice rule for $A$ and $q_{s}$, such that, for any given 
$N_{s}$, the marginal rate of substitution (MRS) between plot size and consumption for a representative squatter is equated to the 'marginal cost' of raising $q_{s}$. To understand this interpretation, consider the no-eviction constraint in (2). An increase in $q_{s}$ reduces the left-hand-side utility of (2) by $N_{s} u_{f q} d q_{s}$. The choice of a bigger plot size $q_{s}$ thus needs to be offset by raising defensive expenditures $A$, which reduces the right-hand-side utility in (2) by $u_{f c} e_{A} / N_{f} d A$. For the no-eviction constraint to remain satisfied, the above-mentioned changes need to be equal, which results in

$$
\frac{\partial A}{\partial q_{s}}=\frac{N_{f} u_{f q}}{u_{f c}} \frac{N_{s}}{e_{A}}
$$

Thus, for a given $N_{s}$, the right-hand-side of (4) can be interpreted as the marginal cost in terms of $A$ of raising $q_{s}$ for a representative squatter. Note here that since this discussion holds $N_{s}$ fixed, it will continue be relevant in the free-migration case, where $N_{s}$ is exogenously determined.

Next, for a given $\left(A, q_{s}\right)$ pair, the optimal choice of $N_{s}$ is determined by the appendix condition in (46). To understand this condition, again consider the no-eviction constraint (2). A change in $N_{s}$ changes the left-hand-side utility by $-u_{f q} q_{s} d N_{s}$ and the right-handside utility by $-u_{f c} e_{N s} / N_{f} d N_{s}$. Again, these two effects need to be equalized for the no-eviction constraint to hold as an equality, which results in an implicit solution for $q_{s}$ in terms of the other two choice variables:

$$
q_{s}=\frac{u_{f c}}{N_{f} u_{f q}} e_{N s}
$$

Thus, the optimum plot size $q_{s}$ equals the inverse MRS between open space and consumption for a representative formal resident adjusted by the marginal eviction-cost benefit of $N_{s}$. Note that the marginal utility of open space is summed over $N_{f}$ formal residents due to the public-good nature of open space. Later, when simplifying functional form assumptions on utility are made, this solution for $q_{s}$ will result in a simpler optimization problem for the squatter-organizer. 
Combining (4) and (6) yields another simple optimization rule:

$$
\frac{u_{s q}}{u_{s c}}=\frac{e_{N s}}{e_{A}} \frac{N_{s}}{q_{s}}
$$

This condition requires that at the optimum, the MRS between plot size and consumption for a representative squatter equals the ratio of marginal eviction-cost benefit from an additional squatter to the marginal eviction-cost benefit from additional defensive expenditures. The respective benefits are weighted by the total number of squatters $N_{s}$ and the plot size $q_{s}$.

\subsection{Assumption of Linear Utility Functions}

A comparative-static analysis of the model is intractable in general or even with Cobb-Douglas (or quasi-linear) utility functions. Hence, for tractability of results, linear utility functions for formal residents and squatters are assumed. Although, as will be seen further in the analysis, this simplification results in a loss of certain nuances, it helps to focus attention on a significant feature of the model: the eviction-cost function. The $e\left(A, N_{s}\right)$ function has not been given much structure so far, but necessary conditions on its form, which can be intuitively justified, are derived later in this section.

With $u_{s}$ and $u_{f}$ linear in their respective arguments, a representative squatter's utility is

$$
u_{s}\left(y_{s}-A, q_{s}\right)=y_{s}-A+\alpha q_{s}
$$

where $\alpha$ is the squatter's constant marginal utility of plot size. With linear formal utility, the no-eviction constraint becomes

$$
y_{f}+\beta\left[\overline{L_{G}}-N_{s} q_{s}\right] \geq y_{f}-\frac{e\left(A, N_{s}\right)}{N_{f}}+\beta \overline{L_{G}},
$$

where $\beta$ is a representative formal resident's constant marginal utility of open space.

When it holds as an equality, (9) provides a solution for $q_{s}$ in terms of the variables 
$A$ and $N_{s}$ :

$$
q_{s}=\frac{e\left(A, N_{s}\right)}{\beta N_{f} N_{s}}=\frac{\theta}{\alpha} f\left(A, N_{s}\right)
$$

where $\theta=\alpha / \beta N_{f}$ and $f\left(A, N_{s}\right)=e\left(A, N_{s}\right) / N_{s}$, or eviction cost per squatter. ${ }^{11}$

The squatter organizer's maximization problem can be simplified by substituting for $q_{s}$ from (10) in the squatter utility function (8). The maximization problem is now unconstrained, with the choice variables reducing to $A$ and $N_{s}$. Thus, the problem can be presented as

$$
\max _{A, N_{s}} \quad y_{s}-A+\theta \frac{e\left(A, N_{s}\right)}{N_{s}} \equiv y_{s}-A+\theta f\left(A, N_{s}\right)
$$

The first-order conditions for optimization with respect to $A$ and $N_{s}$ are

$$
\begin{aligned}
-1+\theta f_{A}\left(A, N_{s}\right) & =0 \\
\theta f_{N_{s}}\left(A, N_{s}\right) & =0 .
\end{aligned}
$$

These conditions characterize the solution for $A$ and $N_{s}$. Along with the implicit solution for $q_{s}$ in (10), equations (12) and (13) provide the full solution to the squatter-organizer's problem under the assumption of linear utilities. The second-order maximization conditions are presented in Appendix A.2.

The condition in (12) requires $f_{A}=1 / \theta$. Since $f_{A}=e_{A} / N_{s}$, this condition can be rewritten as

$$
e_{A}=\frac{\beta}{\alpha} N_{s} N_{f}
$$

Thus, the marginal eviction-cost benefit from defensive expenditures is equated to the ratio of squatter to formal resident marginal utilities weighted by the product of the formal and squatter populations.

Next, notice from (11) that $N_{s}$ is chosen to maximize the function $f\left(A, N_{s}\right)$, which 
is the eviction cost per squatter $e\left(A, N_{s}\right) / N_{s}$. From (13), this maximization requires

$$
f_{N_{s}}=\frac{1}{N_{s}}\left(e_{N s}-\frac{e}{N_{s}}\right)=0
$$

For the bracketed term to equal zero, marginal eviction cost $\left(e_{N s}\right)$ must equal average eviction cost $\left(e / N_{s}\right)$. This condition is illustrated in Figure 1, which shows a U-shaped average eviction-cost function along with a marginal eviction-cost function, which cuts the average-cost function from above. At the point of intersection, marginal eviction cost equals average eviction cost, indicating that $e\left(A, N_{s}\right) / N_{s}$ has reached its maximum. For the maximization problem in (11), to have a proper solution, the function $e\left(A, N_{s}\right) / N_{s}$ must take the form illustrated in Figure $1 .{ }^{12}$

Mathematically, a higher $N_{s}$ has two opposing effects on the average eviction cost. While $N_{s}$ reduces the $e / N_{s}$ ratio by making the denominator larger, it also raises the ratio by making the numerator larger. The ratio is maximized only when these two effects balance out. Intuitively, to maximize $e / N_{s}$, the squatter population $N_{s}$ should be increased as long as its benefit in terms of increasing eviction cost $\left(e_{N s}\right)$ is greater than the loss resulting from spreading this cost over more squatters (captured by $e / N_{s}$ ).

\section{Further Implied Restrictions on Eviction Cost}

The first- and second-order maximization conditions (refer to Appendix A.1 and A.2), provide additional restrictions on the form of $e\left(A, N_{s}\right)$, which help to further pin down the required properties of the function. Recalling from (10) that $f\left(A, N_{s}\right)=$ $e\left(A, N_{s}\right) / N_{s}$, the condition in (47) implies $e_{A A}<0$. Thus, the eviction-cost function (which is increasing) must also be concave in $A$, so that an extra dollar spent on defensive expenditure increases the cost of eviction but at a decreasing rate. This condition, in turn, implies that the eviction cost function must be subject to the standard law of diminishing marginal returns with respect to defensive expenditures. 
The second-order derivative of $f\left(A, N_{s}\right)$ with respect to $N_{s}$ is

$$
f_{N_{s} N_{s}}=\frac{1}{N_{s}^{3}}\left(N_{s}^{2} e_{N s N s}-2\left(N_{s} e_{N s}-e\right)\right)
$$

Since, from (15), the term multiplying 2 in (16) is zero at the optimum, (48) requires $e_{N s N s}<0$ must hold at the optimum. ${ }^{13}$ Thus, this condition requires that marginal eviction cost must be decreasing at the optimum, as seen in Figure 1.

No simple implications for the form of $e\left(A, N_{s}\right)$ can be drawn from condition (49). It can be shown, however, that (49) equals zero if $e$ depends only on the product of $A$ and $N_{s}$, being written as $e\left(A N_{s}\right)$. Thus, such a functional form would violate the second-order condition and, hence, is not admissible.

For the comparative-static analysis, the following inequality will be assumed to hold:

$$
f_{A N s}<0
$$

Since, using (15), $f_{A N s}$ has the same sign as $e_{A N s}-e_{A} / N_{s}$, a sufficient condition for (17) to hold is $e_{A N s} \leq 0$. This condition makes intuitive sense since $e_{A N s} \leq 0$ means that the marginal eviction-cost benefit of defensive expenditures $A$ is smaller when more squatters $N_{s}$ are present. In other words, $A$ is less effective when the other deterrent to eviction (a mass of protesting squatters) is more operative.

\subsection{Comparative-Static Analysis}

Despite the simple linear form for utility, closed form solutions for the choice variables cannot be derived. A comparative-static analysis, however, can still be undertaken. Using Cramer's Rule, the effects of an increase in $\theta$ on $A$ and $N_{s}$ are (refer to Appendix 
A.3 for a detailed derivation)

$$
\begin{aligned}
\frac{\partial A}{\partial \theta} & =\frac{-f_{N s N s}}{\theta^{2}\left(f_{A A} f_{N s N s}-f_{A N s}^{2}\right)}>0 \\
\frac{\partial N_{s}}{\partial \theta} & =\frac{f_{A N s}}{\theta^{2}\left(f_{A A} f_{N s N s}-f_{A N s}^{2}\right)}<0 .
\end{aligned}
$$

The signs in (18) and (19) follow since the denominator is positive from (49), $f_{N s N s}<0$ from the second order condition in (48), and $f_{A N s}$ is assumed to be negative.

Recall that $\theta=\alpha / \beta N_{f}$, so that $\theta$ is directly related to $\alpha$ while being inversely related to $\beta$ and $N_{f}$. Thus, the comparative-static effects of the three $\theta$ components on $A$ and $N_{s}$ can be derived directly from the above results. Also, using the implicit solution for $q_{s}$ as a function of $A$ and $N_{s}$ in (10), the comparative-static effects on $q_{s}$ can also be derived. These effects are summarized in Table (1).

The effects of an increase in the squatters' marginal-utility of plot size $\alpha$ are intuitively straightforward. A higher $\alpha$ implies that squatters prefer a bigger plot size, implying that a higher $q_{s}$ should emerge. Further, squatters would be willing to undertake higher defensive expenditures $A$ in order to protect their tenancy on these bigger plots by raising the eviction cost. The choice of $N_{s}$ is affected by two opposing forces: higher $N_{s}$ would raise the eviction cost but would also result in more fellow-squatters competing for plot size. The latter of these effects dominates so that an increase in $\alpha$ is accompanied by a smaller number of squatters at the optimum. While these effects of $\alpha$ on $A$ and $N_{s}$ are given directly by (18) and (19), the effect on $q_{s}$ is derived by differentiating (10), which yields

$$
\frac{\partial q_{s}}{\partial \alpha}=\frac{e_{A}}{\beta N_{f} N_{s}} \frac{\partial A}{\partial \alpha}+\frac{1}{\beta N_{f} N_{s}}\left(e_{N s}-\frac{e_{N s}}{N_{s}}\right) \frac{\partial N_{s}}{\partial \alpha}>0
$$

where the sign follows from (19) and the fact that the last term is zero by (15).

The intuition behind the effects of an increase in marginal utility from open space 
$\beta$ for formal residents are slightly more tricky to explain. First, notice from (9) that an increase in $\beta$ leads to a stricter no-eviction constraint. ${ }^{14}$ In response, for the equality to be achieved, either less land must be usurped for squatting $\left(N_{s} q_{s}\right.$ falls) or the eviction cost $e\left(A, N_{s}\right)$ must be raised. In this case, $q_{s}$ proves to be the best instrument, so that a smaller plot size is chosen when $\beta$ rises. This result is true because the alternative, choosing a lower $N_{s}$ to reduce total squatting land area, also reduces the eviction cost, which is undesirable. In fact, the squatter-organizer chooses a higher $N_{s}$ in order to raise the eviction cost, which allows $A$ to fall, raising consumption expenditures to offset the loss from the lower $q_{s}$. While the effects of $\beta$ on $A$ and $N_{s}$ are given by (18) and (19), the effect on $q_{s}$ again can be derived from (10). Using (18), it equals

$$
\frac{\partial q_{s}}{\partial \beta}=-\frac{e\left(A, N_{s}\right)}{\beta^{2} N_{f} N_{s}}+\frac{e_{A}}{\beta N_{f} N_{s}} \frac{\partial A}{\partial \beta}<0
$$

where the effect operating through $N_{s}$ is again zero.

Lastly, the effects of a change in $N_{f}$ work in the same direction as $\beta$. With a larger number of formal residents demanding open space, per capita eviction cost is reduced. In response, to prevent eviction, the squatter organizer's goal would be to raise total eviction cost. This goal is achieved by raising $N_{s}$, although $A$ is reduced. The effect on $q_{s}$ is given by

$$
\frac{\partial q_{s}}{\partial N_{f}}=-\frac{e\left(A, N_{s}\right)}{\beta N_{f}^{2} N_{s}}+\frac{e_{A}}{\beta N_{f} N_{s}} \frac{\partial A}{\partial N_{f}}<0,
$$

where the effect operating through $N_{s}$ is again zero.

In understanding the plot size effects, note that although $q_{s}$ is a function of both $A$ and $N_{s}$ as given by (10), changes in each of these variables have different effects on squatter utility. A closer look at the utility function in (8) shows that while a change in $N_{s}$ only affects plot size $q_{s}$, a change in $A$ affects both plot size $q_{s}$ and squatter consumption. Hence, using $N_{s}$ as an instrument to increase the eviction cost proves to be a better strategy than raising $A$, which would result in lower disposable income for squatters as 
well as a demand for bigger plot sizes.

Finally, note that the decision variables are independent of the formal income $y_{f}$, squatter income $y_{s}$ and the total amount of government land $\overline{L_{G}}$ available in the city. This result follows directly due to the linear utility assumptions. The gain is the model's ability to highlight the importance of eviction cost in determining the number of squatters and the amount of land usurped by them.

\section{Free-Migration Model}

Squatters wish to migrate into the city as a result of a gap in rural-urban utility levels. So far, the squatter-organizer has been able to choke off this migration at the optimal point in order to maximize squatter utility. But if the organizer lacks this power, he cannot control the size of the squatter population. This section analyzes such a freemigration situation, which is analogous to the 'open-city' urban model.

\subsection{General Set-up}

In this new set-up, squatters continue to migrate into the city as long as their utility is above the prevailing rural utility. Thus, $N_{s}$ continues to rise as long as $u_{s}\left(y_{s}-A, q_{s}\right)>\widetilde{u}$, where $\widetilde{u}$ is the exogenously fixed level of rural utility. In a 'migration equilibrium,' squatter migration would stop when this condition is satisfied as an equality. This condition would then determine the number of squatters $\widetilde{N}_{s}$ in the city, so that $N_{s}$ is no longer a decision variable for the organizer.

In such a free-migration case, the squatter-organizer continues to maximize (1) by the choice of $A$ and $q_{s}$, subject to the no-eviction constraint given by (2), while $N_{s}$ is now determined by the migration equilibrium condition

$$
u_{s}\left(y_{s}-A, q_{s}\right)=\widetilde{u} .
$$


At the solution to this problem, the first-order conditions with respect to $A$ and $q_{s}$ from the controlled-migration case continue to hold. Hence, the choice rule (4), the no-eviction constraint (2) and the migration equilibrium condition (23) jointly determine the solution to the organizer's optimization problem in the free-migration case.

\subsection{Assumption of Linear Utility Functions}

In order to further analyze the free-migration model, it is useful to once again impose the linearity assumptions on squatter and formal resident utility functions. Conditional on $N_{s}$, the squatter-organizer again chooses $A$ to maximize $y_{s}-A+\theta f\left(A, N_{s}\right)$. The first-order condition is (12), and it yields a solution for $A$ as a function of $\theta$ and $N_{s}$, $A\left(\theta, N_{s}\right)$. Totally differentiating (12) provides the partial effects of these two variables on $A$ :

$$
\frac{\partial A}{\partial N_{s}}=-\frac{f_{A N s}}{f_{A A}}<0 \quad \text { and } \quad \frac{\partial A}{\partial \theta}=-\frac{f_{A}}{\theta f_{A A}}>0
$$

where the signs follow from $f_{A}>0, f_{A A}<0$ and the assumption that $f_{A N s}<0$.

For the free-migration case, while (12) continues to hold, the linear version of the migration equilibrium condition (23) (with $A\left(\theta, N_{s}\right)$ substituted for $A$ ) determines $\widetilde{N_{s}}$ :

$$
y_{s}-A\left(\theta, \widetilde{N_{s}}\right)+\theta f\left(A\left(\theta, \widetilde{N_{s}}\right), \widetilde{N_{s}}\right)=\widetilde{u}
$$

Note that if the squatter-organizer could instead control $N_{s}$, he would choose it to maximize $y_{s}-A\left(\theta, N_{s}\right)+\theta f\left(A\left(\theta, N_{s}\right), N_{s}\right)$. The first-order maximization condition for this problem is

$$
A^{\prime}\left(N_{s}\right)\left[-1+\theta f_{A}\right]+\theta f_{N s}=\theta f_{N_{s}}=0
$$

using (12), and it is the same as (13). Let $N_{s}^{*}$ denote the optimal $N_{s}$, which from (26) satisfies $f_{N s}\left(A\left(N_{s}^{*}\right), N_{s}^{*}\right)=0$.

To compare the optimally chosen $N_{s}^{*}$ to $\widetilde{N}_{s}$, refer to Figure $2 .{ }^{15}$ The figure shows squatter utility as a function of $N_{s}$, with $A$ choosen optimally. Using (25), the slope 
of the curve in the figure is $\theta f_{N s}$, which equals zero at $N_{s}^{*}$, where utility is maximized (reaching a level $u^{*}$ ). Since squatters continue to migrate into the city until utility is pushed down to the rural level, the result is a squatter population of $\widetilde{N}_{s}>N_{s}^{*}$. ${ }^{16}$ Thus, squatter migration uncontrolled by the organizer leads to a larger squatter population in

the city. Note that, since the slope of the utility curve is negative at $\widetilde{N_{s}}, \theta f_{N s}<0$ holds at the migration equilibrium.

\subsection{Comparative-Static Analysis}

Although closed form solutions for the choice variables again cannot be derived for the free-migration version of the model, a comparative-static analysis can still be undertaken. The effect of a change in $\theta$ on $N_{s}$ (derived in Appendix A.4) is

$$
\frac{\partial N_{s}}{\partial \theta}=-\frac{f}{\theta f_{N s}}>0
$$

recalling that $f_{N s}<0$ holds at the migration equilibrium. To understand the sign of this effect, consider the migration equilibrium in (25). An increase in $\theta$ would raise the lefthand-side of (25), so that squatter utility is above rural utility $\widetilde{u} . N_{s}$ would have to adjust in order to re-establish the migration equilibrium. An increase in $N_{s}$ reduces squatter utility, which is the desired direction of change to reach the migration equilibrium.

The increase in $N_{s}$ when $\theta$ rises is the reverse of the effect observed in the controlled migration model. To understand this difference, consider Figure 3, which depicts the shift in the squatter utility curve from $u_{s 1}$ to $u_{s 2}$ when $\theta$ rises. To derive this shift, squatter utility is differentiated using the envelope theorem to zero out the effect of an increase in $\theta$ on $A$, which gives

$$
\frac{\partial}{\partial \theta}\left[y_{s}-A\left(\theta, N_{s}^{*}\right)+\theta f\left(A\left(\theta, N_{s}^{*}\right), N_{s}^{*}\right)\right]=f\left(A\left(\theta, N_{s}\right), N_{s}\right)>0 .
$$

Thus, an increase in $\theta$ raises the squatter utility curve. Such an upward displacement 
would push the intersection of $u_{s 2}$ with the $\widetilde{u}$ line further right compared to the $u_{s 1}$ intersection, resulting in a higher value of $N_{s}$ under the free-migration case. Therefore, $\widetilde{N_{s 2}}>\widetilde{N_{s 1}}$ holds.

Next, differentiating the slope expression with respect to $\theta$ gives

$$
\begin{aligned}
\frac{\partial\left[\theta f\left(A\left(\theta, N_{s}^{*}\right), N_{s}^{*}\right)\right]}{\partial \theta} & =f_{N s}+\theta f_{A N s} \frac{\partial A}{\partial \theta} \\
& <0, \text { when } \quad f_{N s} \leq 0 .
\end{aligned}
$$

The above result indicates that, when $\theta$ increases, the slope of the new squatter utility curve $u_{s 2}$ is algebraically less than the slope of the old curve $u_{s 1}$ at all values of $N_{s}$ where it was true that $f_{N s} \leq 0$. In other words, for all $N_{s} \geq N_{s 1}^{*}, u_{s 2}$ is steeper (with a slope that is more negative) than $u_{s 1}$. This conclusion implies that the slope of $u_{s 2}$ is negative (rather than zero) at $N_{s 1}^{*}$. If the utility-curve is single-peaked, it follows that the peak of $u_{s 2}$ would lie to the left of the peak of $u_{s 1}$. The result is a lower value of $N_{s}$ in the controlled migration case, so that $N_{s 2}^{*}<N_{s 1}^{*}$.

To continue with the comparative-static analysis for the free-migration case, recall that since $\theta=\alpha / \beta N_{f}, N_{s}$ falls with an increase in either $\beta$ or $N_{f}$. However, since a change in $\alpha$, by changing the utility function, would require a simultaneous change in the rural utility level $\widetilde{u}$, a change in $\theta$ coming from $\alpha$ is not considered. These effects of $\beta$ and $N_{f}$ are summarized in Table 1, from which it can be seen that effects are reversed compared to the basic model case. Thus, an increase in the number of formal residents $N_{f}$ or an increase in their preference $\beta$ for open space would naturally lead to fewer squatters $N_{s}$ migrating into the city.

As in (53), totally differentiating (25) yields the effect of a change in $y_{s}$ on $N_{s}$ :

$$
\frac{\partial N_{s}}{\partial y_{s}}=-\frac{1}{\theta f_{N s}}>0
$$

where the sign again follows from $f_{N s}<0$. This effect is intuitive in that, ceteris paribus, an increase in squatter income would increase migration into the city, resulting in a higher 
$N_{s}$. Note that although $y_{s}$ had no effects in the basic model under the linear utility assumption, it matters in the free-migration model under the same linearity assumption. Such a result arises because rural-urban squatter income differentials will clearly play a role in determining the migration equilibrium.

An increase in $y_{s}$ has an indirect effect on $A$ operating through $N_{s}$, which (using (24) and (30)) is given by

$$
\frac{\partial A}{\partial y_{s}}=\frac{\partial A}{\partial N_{s}} \frac{\partial N_{s}}{\partial y_{s}}=\frac{1}{\theta} \frac{f_{A N s}}{f_{A A} f_{N s}}<0
$$

The sign follows since $f_{A A}<0, f_{N s}<0$ and $f_{A N s}<0$. Further, recalling that $q_{s}=$ $f\left(A\left(\theta, N_{s}\right), N_{s}\right) / \beta N_{f}$, the effect of an increase in $y_{s}$ on $q_{s}$ is

$$
\frac{\partial q_{s}}{\partial y_{s}}=\theta\left[f_{A} \frac{\partial A}{\partial y_{s}}+f_{N s} \frac{\partial N_{s}}{\partial y_{s}}\right],<0
$$

using the signs from (30) and (31). Note that this result may seem counter-intuitive because a higher income ends up reducing plot size. The explaination comes from the increase in $N_{s}$ caused by a higher $y_{s}$, which leads the squatter-organizer to tighten $q_{s}$ to avoid occupation of an excessive amount of land. ${ }^{17}$

In contrast to these determinate results, the comparative-static effects of $\theta$ on $A$ and $q_{s}$ are both unambigous in sign.

\section{Combined Model of Squatting on Government and Private Land}

This paper started out as an extension of Brueckner and Selod (2009), who present a model of squatting on privately-owned land, and went on to build a model where squatting occurs instead on government-owned land. In fact, squatting is observed on both types of land, and this section presents a combined model analyzing such a situation. 
It will soon become clear that such a model is complex and, hence, it is best to have seen each scenario modeled individually before putting them together, which is the agenda of this current section.

The total land area of the city equals $\bar{L}$, which consists of $L_{P}$ worth of privatelyowned land and $\overline{L_{G}}$ worth of government land, as before. Each of the city's $N_{f}$ formal residents occupies a plot of size $q_{f}$, which is a function of the price per unit $p_{f}$ of formal housing. Both $q_{f}$ and $p_{f}$, which were exogenously fixed and suppressed in the earlier analysis, are now flexible and determined within the model. The representative formal resident's demand function for housing is given by $q_{f}=d\left(p_{f}\right)$.

As in the controlled-migration model, the squatter-organizer chooses the number of squatters $N_{s}$. Additionally, he also chooses the proportion $\delta$ of squatters that will occupy plots on privately-owned land. The remaining $(1-\delta)$ share of squatters occupies government-owned land. For simplicity, assume that plot size $q_{s}$ occupied by each squatter is the same on both types of land. Also, assume that the defensive expenditure $A$ paid by each squatter to protect tenancy is the same on both types of land. The assumptions of common plot sizes and defensive expenditures imply homogeneous squatting-plot characteristics, which means that squatters are indifferent between occupying private or government land. Therefore, the squatter division across land types can be dictated by the squatter-organizer in the process of maximizing squatter utility.

The squatter-organizer continues to maximize representative squatter utility $u\left(y_{s}-\right.$ $\left.A, q_{s}\right)$, with the choice variables being $A, N_{s}, q_{s}$ and $\delta$. Now, the organizer has to take into account two constraints. First, squatters should usurp a small enough amount of government land that formal residents would not want to pay a head tax toward evicting them (the previous no-eviction constraint). Second, as modeled in Brueckner and Selod (2009), the formal housing market should not be squeezed so much that landowners have an incentive to evict the squatters on private land.

Eviction cost continues to be a function of defensive expenditures and the number of squatters occupying the relevant land type. Thus, the total eviction cost for landowners 
is $e\left(A, \delta N_{s}\right)$, while the total eviction cost for the government is $e\left(A,(1-\delta) N_{s}\right)$. While homogeneity of squatting-plot characteristics (same $q_{s}$ and $A$ ), and the resulting indifference of squatters across land-types is a natural assumption, a richer framework that allows different eviction-cost functions for government-owned and privately-owned land might be desirable. Such heterogeneity could arise from differences in the bargaining power of government and private land-owners or possible differences in economies of scale in eviction on the two types of land. However, such a set-up introduces analytical difficulties.

It is now convenient for the analysis to use an indirect utility function $V$ for formal residents, which is a function of formal income, the formal housing price and the amount of open space in the city. Thus, the no-eviction constraint on government land can be expressed as $^{18}$

$$
V_{f}\left(\widetilde{y_{f}}, p_{f}, L_{G}-(1-\delta) N_{s} q_{s}\right) \geq V_{f}\left(\widetilde{y_{f}}-\frac{e\left(A,(1-\delta) N_{s}\right)}{N_{f}}, p_{f}, L_{G}\right) .
$$

Next, landowners tolerate squatting as long as the rent that could be earned in the formal market is less than the eviction cost per-unit-of-land. The no-eviction constraint on private land is therefore

$$
p_{f} \leq \frac{e\left(A, \delta N_{s}\right)}{\delta N_{s} q_{s}}
$$

recalling that $\delta N_{s} q_{s}$ is the amount of squatter-occupied private land. This constraint must be satisfied as an equality since, as long as $p_{f}$ is less than the right-hand-side, the squatter-organizer can choose a higher $q_{s}$ and increase squatter utility without violating the constraint. In practice, this means that the organizer will expand squatter occupation of formal land until landowners are indifferent between tolerating squatting and paying the eviction cost required to convert the land to formal housing.

Naturally, an additional requirement is that the total land area occupied by formal residents $\left(N_{f} q_{f}\right)$ and by squatters on private land $\left(\delta N_{s} q_{s}\right)$ equals the total privately owned 
land area in the city:

$$
L_{P}=N_{f} q_{f}+\delta N_{s} q_{s}=N_{f} d\left(p_{f}\right)+\delta N_{s} q_{s}
$$

Writing (34) as $\delta N_{s} q_{s}=e / p_{f}$ and substituting in (35) yields the single constraint

$$
e\left(A, \delta N_{s}\right)=L_{P} p_{f}-N_{f} d\left(p_{f}\right) p_{f}
$$

which says that the squatter-organizer's optimal choice of $A, N_{s}$ and $\delta$ should be such that the total eviction cost for landowners equals the lost revenue from squatting.

The Lagrangian expression for the squatter-organizer's problem is

$$
\begin{aligned}
L_{c}= & u_{s}\left(y_{s}-A, q_{s}\right)+\lambda_{p v t}\left[e\left(A, \delta N_{s}\right)-L_{P} p_{f}+N_{f} d\left(p_{f}\right) p_{f}\right] \\
& +\lambda_{p u b}\left[V_{f}\left[y_{f}, p_{f}, L_{G}-(1-\delta) N_{s} q_{s}\right]-V_{f}\left[y_{f}-\frac{e\left(A,(1-\delta) N_{s}\right)}{N_{f}}, p_{f}, L_{G}\right]\right] .
\end{aligned}
$$

The first-order conditions for maximization (presented in Appendix A.5), provide some interesting results for the combined model.

After multiplying the appendix condition (56) by $N_{s}$ and comparing the result to (57), it is clear that for both equations to hold, the following condition must be satisfied:

$$
\delta=1-\delta=\frac{1}{2}
$$

Thus, there emerges a simple decision rule for $\delta$, which requires that the squatters be equally split between private and government land. Together with the assumption of same plot sizes, $q_{s}$, on both types of land, this result implies that equal amounts of private and government land are usurped for squatting, equal to $\frac{1}{2} N_{s} q_{s}$. This striking result is independent of all the other parameters of the model. Also, note that the result would likely be overturned if the defensive expenditures and plot sizes for squatting or 
eviction costs were different across land types. ${ }^{19}$

Further, (55) and (56) provide solutions for $\lambda_{p u b}$ and $\lambda_{p v t}$, respectively. Substituting these solutions into (54) and using (38) to substitute for $\delta$ leads to another simple optimization rule, which is same as the condition previously derived in (7):

$$
\frac{u_{s q}}{u_{s c}}=\frac{e_{N s}}{e_{A}} \frac{(1-\delta) N_{s}}{q_{s}}
$$

In contrast to (7), the total number of squatters on government land in (39) is $(1-\delta) N_{s}$.

The combined model presented here shows the ability of the framework to incorporate additional stylized facts. Further work could be carried out to arrive at comparativestatic results after making some functional form assumptions, which might prove particularly useful to empirical researchers analyzing questions on squatting in developing countries.

\section{Policy Analysis: Squatter Formalization}

The model presented above shows that a city's government may not wish to evict squatters, with formal-resident utility-maximization as the underlying objective. Yet, formalization, which involves moving squatter populations to the city's formal housing sector, is an important goal of policymakers in dealing with squatter settlements. The basic model of squatting on government land outlined in Section 2.2 provides a simple framework for analyzing policy interventions designed to achieve such squatter formalization, under which squatters become legitimate rent-paying residents of the city. Note that, for formalization to succeed, all the stakeholders are required to 'buy in' to the policy. Thus, workable formalization should be Pareto-improving. The analysis in this section explores the possibility of such a policy.

Suppose that the government offers the squatters, whose number is fixed at the optimal $N_{s}^{*}$, title to the land they occupy in return for a lump-sum rental payment of $R$ per squatter. The squatters will accept such an offer if the government sets $R$ equal to 
the amount of defensive payments $A^{*}$ required to maintain tenancy as squatters. Recall that these defensive payments made by squatters can be viewed as flowing to several possible recipients. For the sake of this analysis, let us view the defensive expenditures as 'bribes' paid to secure the support of local politicians. The same politicians may require a continuation of these bribes to support formalization, and the government could use the rent $R$ collected from the squatters for this purpose. ${ }^{20}$ Such a policy will not affect the utility of formal residents since the only change is that the land previously squatted on is now legally transferred to squatters, with the amount of open space in the city remaining at $\overline{L_{G}}-N_{s}^{*} q_{s}^{*}$. Thus, squatters can be 'formalized' without making anyone worse-off.

This policy is Pareto-improving only in a weak sense, leaving everyone (including the politicians who lose their bribes) equally well off while achieving squatter formalization. But truly Pareto-improving formalization would involve at least some stakeholders being better-off than under the squatting equilibrium, while leaving no others worse-off than earlier. It is natural that a government working in favor of the formal residents would prefer a policy to be welfare-improving for these residents. In the current framework, such a policy is possible under some circumstances, which the following analysis delineates. The policy intervention outlined attempts to reduce squatting, allowing formal residents to enjoy more open space.

Suppose the government offers the $N_{s}^{*}$ squatters less total land than before, offering some $\widetilde{L}<N_{s}^{*} q_{s}^{*}{ }^{21}$ Thus, each squatter is transferred the title for a land plot smaller than $q_{s}^{*}$, the size of the previously occupied plot. In such a case, in order to remain at the previously attained utility level $u^{*}$, the squatters would only be willing to pay an amount $R<A^{*}$ in rent. This amount, now, will not be sufficient to replace the bribes paid earlier. Note, however, that the formal residents are better-off than before since they enjoy more open space. As a result, the government can collect a positive head $\operatorname{tax} K$ from each formal resident and still maintain the level of utility achieved with squatting. Could the combined rent and head tax revenue be sufficient to compensate the politicians, so that such a scheme is utility-enhancing for all parties? The following 
analysis provides an answer. But, first, note that the analysis is carried out by focusing on a small deviation from the optimum in the basic model. Thus, the quest is to look for a 'marginal' Pareto-improvement, based on a 'small' reduction in $\widetilde{L}$ below $N_{s}^{*} q_{s}^{*}$.

To carry out the analysis, observe first that both $R$ and $K$ are functions of $\widetilde{L}$. To see the dependence of $R$ on $\widetilde{L}$, note that in order to maintain squatters at the level of utility $u_{s}^{*}, R$ must satisfy $u_{s}\left(y_{s}-R, \widetilde{L} / N_{s}\right)-u_{s}^{*}=0$, where $q_{s}=\widetilde{L} / N_{s}$. Thus, the effect of a change in $\widetilde{L}$ on $R$ is given by

$$
\frac{\partial R}{\partial \widetilde{L}}=-\frac{\partial u_{s} / \partial \widetilde{L}}{\partial u_{s} / \partial R}=\frac{1}{N_{s}} \frac{u_{s q}}{u_{s c}}>0 .
$$

Thus, as $\widetilde{L}$ falls, $R$ falls at a rate equal to $1 / N_{s}$ times the squatter MRS.

On the other hand, now that more open space will be made available to formal residents, the government can collect $K$ from each formal resident while maintaining the previous utility level $u_{f}^{*}$. K must satisfy $u_{f}\left(y_{f}-K, L_{G}-\widetilde{L}\right)-u_{f}^{*}=0$. Thus, the effect of a change in $\widetilde{L}$ on $K$ is given by

$$
\frac{\partial K}{\partial \widetilde{L}}=-\frac{\partial u_{f} / \partial \widetilde{L}}{\partial u_{f} / \partial k}=-\frac{u_{f q}}{u_{f c}}<0
$$

Thus, as $\widetilde{L}$ falls, $K$ rises at a rate equal to the formal MRS.

Now, when $\widetilde{L}=N_{s}^{*} q_{s}^{*}$, it follows that $R=A^{*}$ and $K=0$, so that $N_{s} R+N_{f} K=$ $N_{s} A^{*}$. Therefore, if

$$
\frac{\partial\left(N_{s} R+N_{f} K\right)}{\partial \widetilde{L}}<0
$$

holds, then $N_{s} R+N_{f} K>N_{s} A^{*}$ must be true for $\widetilde{L}$ marginally below $N_{s}^{*} q_{s}^{*}$, indicating the possibility of a Pareto-improving squatter formalization. Combining (40) and (41) 
yields the sign of the above effect:

$$
\begin{aligned}
\frac{\partial\left(N_{s} R+N_{f} K\right)}{\partial \widetilde{L}} & =N_{s} \frac{\partial R}{\partial \widetilde{L}}+N_{f} \frac{\partial K}{\partial \widetilde{L}}=\frac{u_{s q}}{u_{s c}}-N_{f} \frac{u_{f q}}{u_{f c}} \\
& =\left(1-\frac{e_{A}}{N_{s}}\right) \frac{u_{s q}}{u_{s c}}
\end{aligned}
$$

The sign of (43) is in general indeterminate, depending on the magnitude of $e_{A} / N_{s}$ at the optimum. However, in the linear utility case, $e_{A} / N_{s}=1 / \theta$ from (12), so that (43) has the sign of $1-1 / \theta=1-\beta N_{f} / \alpha$. Therefore, in the linear case, negativity of (43) requires $\alpha<\beta N_{f}$. Thus, a Pareto-improving squatter formalization is possible if $\beta$ is not too small relative to $\alpha$. This condition makes intuitive sense since an increase in

$N_{s} R+N_{f} K$ as $\widetilde{L}$ falls would occur only if $N_{f} K$ rises faster than $N_{s} R$, which requires that the value $\beta$ of open space to formal residents is sufficiently larger than the value $\alpha$ of plot size to squatters. Empirically, a small value of the $\beta$ parameter can be expected if formal residents do not care much for government-owned land in the city, which is likely to be the case for marginal land under government jurisdiction, as described earlier.

\section{Conclusion}

The paper has presented a framework for analysis of squatting on government land in developing countries. It has built a basic model wherein a squatter-organizer maximizes squatter utility by optimally choosing the size of the squatter population, the plot size occupied by each squatter household, and the level of defensive expenditures. These choices are made such that the government, which acts in the interest of the city's formal residents, has no incentive to evict the squatters. The paper has also modelled the free-migration case, in which the squatter-organizer cannot control squatter migration into the city. Under the assumption of linear utilities, comparative-static results for both the cases have been derived and contrasted. The paper has also outlined a framework 
for a combined model of squatting on government and private land, adding some insights to the ones presented by Brueckner and Selod (2009). Lastly, using the model's results, a policy-analysis exercise has been carried out to find conditions under which squatter formalization could be Pareto-improving.

Several extensions of the model could be explored by either relaxing some assumptions or introducing interactions between existing variables. Labor complementarity between the formal residents and squatters, which would make formal incomes an increasing function of the number of squatters in the city, could be introduced. A profit-maximizing squatter organizer, rather than a benevolent one, could be modeled. A quality difference between squatter and formal housing could be introduced in the combined model. Issues related to land servicing (public utilities, roads, infrastructure, etc) could be included and addressed as well.

Finally, some of the model's predictions could be empirically tested, perhaps using the more-realistic free-migration framework. That version of the model predicts that the size of the squatter population is larger the smaller is $\beta$ (the worse the quality of government land), the smaller is the formal population $N_{f}$, and the larger is the income earned by squatters in the city. Also, though the amount of government land $\overline{L_{G}}$ drops out of the analysis under the linear utility assumption, it might be expected that a larger $\overline{L_{G}}$ would encourage more squatting. With suitable data, the accuracy of these predictions could be appraised. 


\section{A Appendix}

\section{A.1 First-order maximization conditions}

Using (3), the first-order maximization conditions for the basic model are

$$
\begin{aligned}
\frac{\partial L}{\partial A} & =-u_{s c}+\lambda u_{f c} \frac{e_{A}}{N_{f}}=0 \\
\frac{\partial L}{\partial q_{s}} & =u_{s q}-\lambda u_{f q} N_{s}=0 \\
\frac{\partial L}{\partial N_{s}} & =-u_{f q} q_{s}+u_{f c} \frac{e_{N s}}{N_{f}}=0 .
\end{aligned}
$$

\section{A.2 Second-order maximization conditions}

The second-order conditions for the maximization problem are

$$
\begin{array}{r}
f_{A A}<0, \\
f_{N s N s}<0, \\
f_{A A} f_{N s N s}-f_{A N s}^{2}>0,
\end{array}
$$

where $f_{A A}$ and $f_{N s N s}$ are the second-order partial derivatives of $f\left(A, N_{s}\right)$ with respect to $A$ and $N_{s}$, respectively, and $f_{A N s}$ is the cross partial derivative.

A.3 Using Cramer's Rule to derive comparative-static effects

Total differentiation of the first-order conditions in (12) and (13) yields

$$
\begin{array}{r}
f_{A} \mathrm{~d} \theta+\theta f_{A A} \mathrm{~d} A+\theta f_{A N_{s}} \mathrm{~d} N_{s}=0 \\
f_{N_{s}} \mathrm{~d} \theta+\theta f_{A N_{s}} \mathrm{~d} A+\theta f_{N_{s} N_{s}} \mathrm{~d} N_{s}=0
\end{array}
$$


Transforming to matrix form and substituting $f_{A}=1 / \theta$ and $f_{N_{s}}=0,(50)$ and (51) can be written as

$$
\left[\begin{array}{ll}
f_{A A} & f_{A N s} \\
f_{A N s} & f_{N s N s}
\end{array}\right]\left[\begin{array}{c}
\mathrm{d} A \\
\mathrm{~d} N_{s}
\end{array}\right]=\left[\begin{array}{c}
-1 / \theta^{2} \\
0
\end{array}\right] \mathrm{d} \theta
$$

Solving (52) for the derivatives yields (18) and (19).

A.4 Deriving the effect of $\theta$ on $N_{s}$ in the free-migration case

Total differentiation of (25) yields

$$
\left[f+\left(1-\theta f_{A}\right)\left(\frac{\partial A}{\partial \widetilde{N}_{s}} \frac{\partial \widetilde{N_{s}}}{\partial \theta}+\frac{\partial A}{\partial \theta}\right)\right] \mathrm{d} \theta-\left[\left(1-\theta f_{A}\right) \frac{\partial A}{\partial \widetilde{N}_{s}}-\theta f_{N s}\right] \mathrm{d} \widetilde{N}_{s}=0
$$

Using $-1+\theta f_{A}=0$ from (12) to eliminate terms and rearranging, (53) gives (27). 
A.5 First-order maximization conditions for the combined model

Using (37), the first-order maximization conditions for the combined model are:

$$
\begin{aligned}
& \frac{\partial L_{c}}{\partial A}=-u_{s c}+\lambda_{p v t} e_{A}\left(A, \delta N_{s}\right)-\lambda_{p u b} \frac{V_{f c}}{N_{f}} e_{A}\left(A,(1-\delta) N_{s}\right)=0 \\
& \frac{\partial L_{c}}{\partial q_{s}}=u_{s q}-\lambda_{p u b} V_{f q}(1-\delta) N_{s}=0 \\
& \frac{\partial L_{c}}{\partial N_{s}}=\lambda_{p v t} \delta e_{N s}\left(A, \delta N_{s}\right)-\lambda_{p u b}(1-\delta)\left[\frac{V_{f c}}{N_{f}} e_{N s}\left(A,(1-\delta) N_{s}\right)-V_{f q} q_{s}\right]=0
\end{aligned}
$$

$$
\frac{\partial L_{c}}{\partial \delta}=\lambda_{p v t} N_{s} e_{N s}\left(A, \delta N_{s}\right)+\lambda_{p u b} N_{s}\left[\frac{V_{f c}}{N_{f}} e_{N_{s}}\left(A,(1-\delta) N_{s}\right)-V_{f q} q_{s}\right]=0
$$

$$
\frac{\partial L_{c}}{\partial p_{f}}=\lambda_{p v t}\left[-L_{P}+N_{f} p_{f} d^{\prime}\left(p_{f}\right)+N_{f} d\left(p_{f}\right)\right]=0
$$

\section{B Tables and Figures}




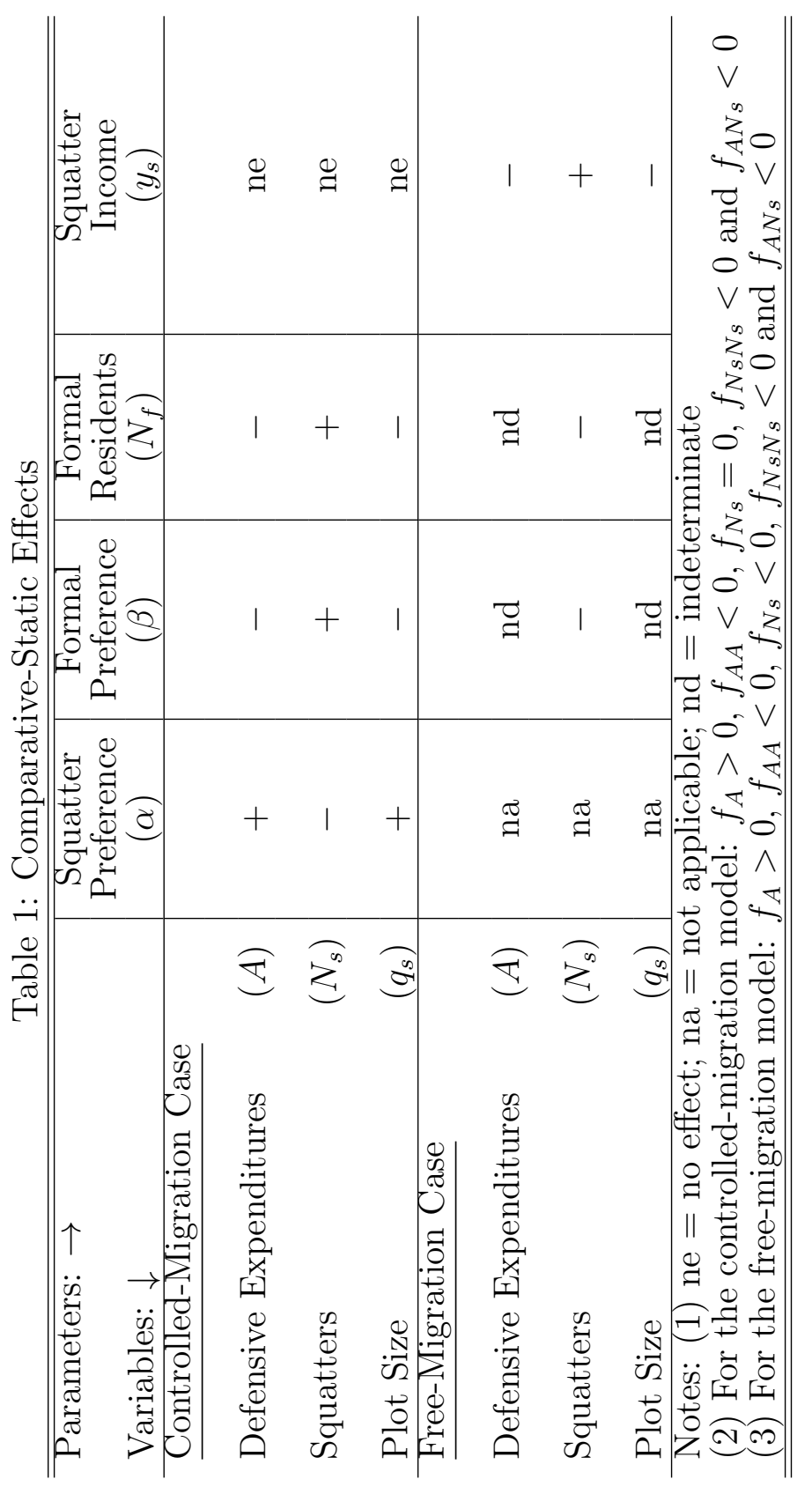




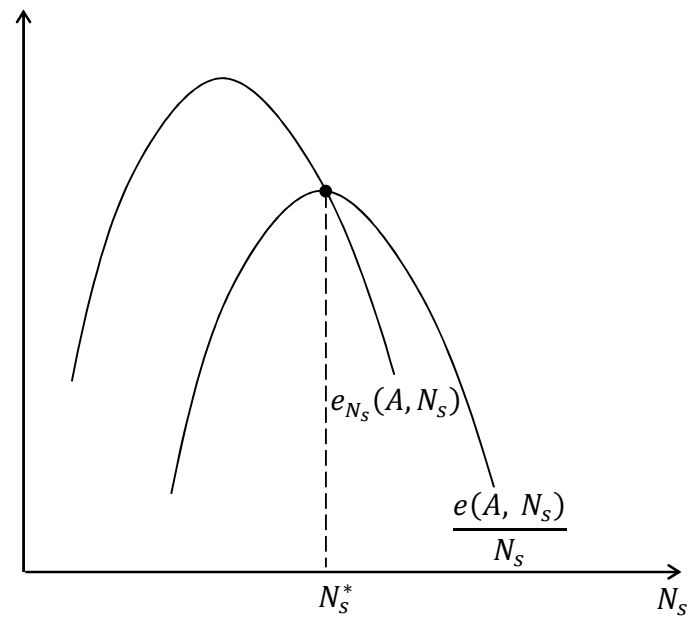

Figure 1: The determination of optimal $N_{s}$

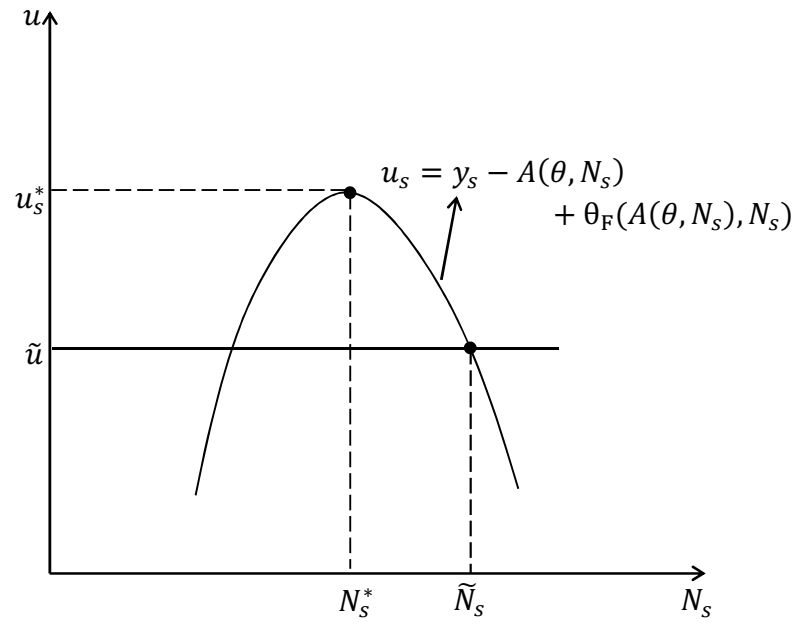

Figure 2: The free-migration case

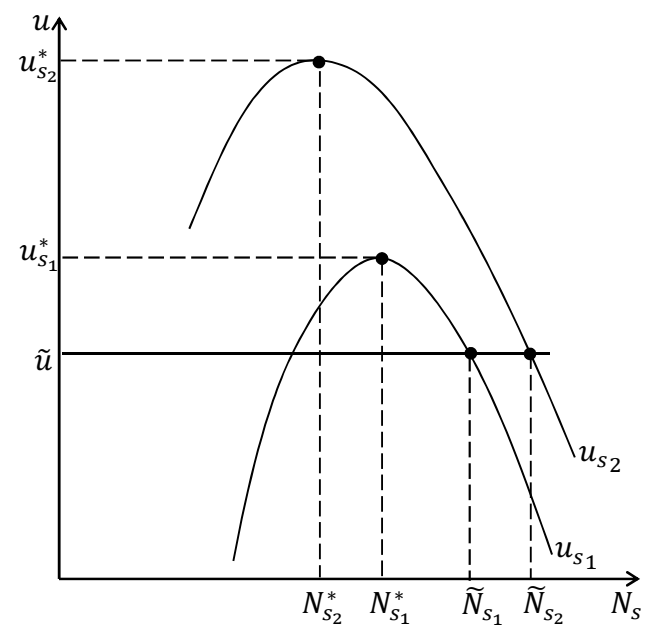

Figure 3: The effect of an increase in $\theta$ on optimal $N_{s}$ 


\section{References}

Brueckner, J., And H. Selod (2009): "A Theory of Urban Squatting and LandTenure Formalization in Developing Countries," American Economic Journal: Economic Policy, 1, 28 - 51.

Field, E. (2005): "Property Rights and Investment in Urban Slums," Journal of the European Economic Association, Papers and Proceedings, 3, 279 - 290.

FiELD, E. (2007): "Entitled to Work: Urban Property Rights and Labor Supply in Peru," Quarterly Journal of Economics, 122, 1561 - 1602.

Flood, J. (2006): Secure Tenure Survey Final Report, Urban Growth Management Initiative.

Friedman, J., E. Jimenez, and S. K. Mayo (1988): "The Demand for Tenure Security in Developing Countries," Journal of Development Economics, 29, 185 - 198.

Hoy, M., And E. Jimenez (1991): "Squatters' Rights and Urban Development: An Economic Perspective," Economica, 58, 79 - 92.

Jha, S., V. RaO, and M. Woolcock (2007): "Governance in Gullies: Democratic Responsiveness and Leadership in Delhi's Slums," World Development, 35(2), 230 246.

Jimenez, E. (1984): "Tenure Security and Urban Squatting," The Review of Economics and Statistics, 66, 556-567.

Jimenez, E. (1985): "Urban Suatting and Community Organization in Developing Countries," Journal of Public Economics, 27, 69 - 92.

Lall, S. V., M. K. Lundberg, and Z. Shalizi (2008): "Implications of Alternate Policies on Welfare of Slum Dwellers: Evidence from Pune, India," Journal of Urban Economics, 63, $56-73$. 
Lanjouw, J. O., And P. I. Levy (2002): "Untitled: A Study of Formal and Informal Property Rights in Urban Ecuador," Economic Journal, 112, 986 - 1019.

Laquain, A. A. (1972): Slums and Squatters in Six Philippine Cities, . International Development Research Centre, Ottawa,Ont., CA.

Mangin, W. (1967): "Latin American Squatter Settlements: A Problem and a Solution," Latin American Research Review, 2(3), 65 - 98.

Sinn, H.-W. (1986): "Vacant Land and the Role of Government Intervention," Regional Science and Urban Economics, 16, 353 - 385.

Takeuchi, A., M. Cropper, and A. Bento (2008): "Measuring the Welfare Effects of Slum Improvement Programs: The Case of Mumbai," Journal of Urban Economics, $64,65-84$.

Turnbull, G. K. (2008): "Squatting, Eviction and Development," Regional Science and Urban Economics, 38, 1 - 15.

United Nations Habitat (2009): Planning Sustainable Cities: Global Report on Human Settlements, United Nations Human Settlements Programme (UN-Habitat), London and Sterling, VA.

World Bank (2007): Dhaka: Improving Living Conditions for the Urban Poor, World Bank, Bangladesh Development Series Paper No. 17. 


\section{Notes}

${ }^{1}$ The percentages represent the average of land invasions that are on public land for all cities in the region.

${ }^{2} \operatorname{Sinn}(1986)$ points out that land free of current 'structural commitments' has characteristics similar to a natural resource, and so maintaining land as vacant (or at least free of structures that are costly to remove) may well reflect its most efficient current use. This property of vacant land is especially true in the case of government-owned land, whose most efficient use might be that of public open space for the recreation and pleasure of the city's residents.

${ }^{3}$ Mangin (1967) noticed some forty years ago that associations in the squatter settlements of Peru "do seem to be able to control, to a certain extent, who will be members of the [land] invasion group."

${ }^{4}$ More recent empirical work on squatting uses data on several Indian cities. Jha, Rao, and Woolcock (2007) combine econometric analysis with qualitative ethnographic surveys on slums in Delhi to examine informal governance structures that evolve within slums and the role of slum leaders in gaining access to formal government services for squatters. A study on Pune by Lall, Lundberg, and Shalizi (2008) evaluates alternative policy interventions leading to squatter resettlement while taking into account slumdwellers' valuation of location-based amenities. Another paper by Takeuchi, Cropper, and Bento (2008) estimates the welfare effects of slum improvement programs (in-situ slum upgradation versus relocation of slum households) in Mumbai using a discrete residential location choice model.

${ }^{5}$ According to Flood (2006), cities where the eviction of squatters is very frequent include Guangzhou (China), Harare (Zimbabwe), Mumbai (India) and Valledupar (Columbia). However, cities where evictions are rare include Guadalajara (Mexico), Ho Chi Minh City (Vietnam), Istanbul (Turkey), Sao Paulo (Brazil), and Tehran (Iran) (where no evictions at all were reported).

${ }^{6}$ The eviction cost per-unit-of-land in this model is $e\left(A, N_{s}\right) / N_{s} q_{s}$, where $q_{s}$ is the plot size occupied by each squatter household and $N_{s} q_{s}$ hence represents the total land area usurped for squatting. This distinction will become important later in the analysis of the combined model of squatting on private and government land.

${ }^{7}$ Alternatively, the squatter-organizer's objective could be to maximize total squatter utility $N_{s} u\left(y_{s}-\right.$ $\left.A, q_{s}\right)$. However, this approach would further complicate the analysis. The current paper follows the convention of considering representative squatter utility, as in the BS model.

${ }^{8} \mathrm{~A}$ richer model would allow for both population sizes to be endogenous. This assumption of exogenously fixed $N_{f}$ allows the analysis to focus on the impact of squatter migration into a city with an established formal population. Additionally, a fixed assignment of two exogenously specified groups to squatting and formal housing is assumed so that endogenous sorting between the two tenure modes is 
not considered. Refer to Jimenez (1985) for an analysis of squatting as a utility-optimizing tenure choice by households under price and income uncertainty.

${ }^{9}$ Note here that the constraint $\overline{L_{G}} \geq N_{s} q_{s}$ is not explicitly imposed but is assumed to be satisfied.

${ }^{10}$ The paper ignores the possibility of a corner solution where squatters would invade all the public land $\overline{L_{G}}$.

${ }^{11}$ Rearranging the first equality in (10) yields

$$
\frac{e\left(A, N_{s}\right)}{N_{s} q_{s}}=\beta N_{f}
$$

which says that eviction cost per-unit-of-land equals a formal resident's marginal utility of open space times the total number of formal residents. Thus, eviction cost per-unit-of-land on a per-capita basis equals $\beta$. This result makes intuitive sense since a formal resident would not be willing to pay an eviction cost larger than the utility of open space, which under the linear utilities assumption equals $\beta$.

${ }^{12}$ Note that the $e\left(A, N_{s}\right) / N_{s}$ curve is shown to have a positive intercept, since by L'Hopital's Rule,

$$
\lim _{N_{s} \rightarrow 0} \frac{e\left(A, N_{s}\right)}{N_{s}}=\lim _{N_{s} \rightarrow 0} \frac{e_{N s}\left(A, N_{s}\right)}{1},
$$

which is greater than zero.

${ }^{13}$ Note from Figure 1 that $e_{N s N s}$ cannot be negative for smaller values of $N_{s}$.

${ }^{14}$ Note that the stricter nature of the constraint becomes clear under the linear utility assumptions because the $L_{G}$ terms in (9) cancel from both sides, with a higher $\beta$ resulting in a reduction in the remaining left-hand-side expression.

${ }^{15}$ Note that Figures 1 and 2 depict different functions. In Figure 1, the U-shaped curve represents the average eviction cost $f\left(A, N_{s}\right)=e\left(A, N_{s}\right) / N_{s}$. In Figure 2, the U-shaped curve is the squatter utility function $y_{s}-A\left(\theta, N_{s}\right)+\theta f\left(A\left(\theta, N_{s}\right), N_{s}\right)$.

${ }^{16}$ Note that rural utility $\widetilde{u}$ cannot be higher than $u^{*}$ since squatters would then want to out-migrate into the rural areas.

${ }^{17}$ Note here that there is a limit to the total amount of land $N_{s} q_{s}$ that can be usurped for squatting. While $\overline{L_{G}}$ fixes a natural upper limit, the marginal utility of open space for formal residents might enforce a stricter upper limit. In particular, under more general functional form assumptions, the assumption that $u_{f q} \rightarrow \infty$ as open space approaches zero would limit the amount of open space that can be usurped for squatting while maintaining satisfaction of the no-eviction constraint.

${ }^{18}$ Note here that $\widetilde{y_{f}}$ is the gross (pre-rent) income of formal residents, as explained in the description of the basic model. 
${ }^{19} \mathrm{An}$ analysis assuming an exogenously given $\delta$ can be undertaken. In this case, the effect of an increase in $\delta$ on formal utility can be evaluated by using the following derivative:

$$
\frac{\mathrm{d}}{\mathrm{d} \delta} V_{f}\left(y_{f}, p_{f}(\delta), L_{G}-(1-\delta) N_{s}(\delta) q_{s}(\delta)\right)
$$

${ }^{20}$ Earlier in the paper we also discussed the possiblity that the defensive expenditures can be used to hire 'guards' to protect the tenancy of squatters on the land they occupy. In such a scenario, two possible outcomes are possible. If the guards can be employed elsewhere when they are not needed to protect the squatters, no compensation to them is required. Alternatively, existence of unemployment in the city, which seems realistic in a developing-country context, would imply that the guards would not find alternative jobs with formalization. In this case, the rent $R$ would be used to compensate the guards. Alternatively, defensive expeditures can viewed as labor income forgone by squatters. In this case, the squatters can work more hours and, hence, earn more wages. However, there arises a disutility from working more hours due to a reduction in leisure time. This loss can, again, be compensated using $R$. If work leaves no surplus for workers, with the disutility of labor exactly canceling the gain from the extra income, then the entire amount $R$ would need to be returned to the squatters in compensation. If some surplus remains, however, then less compensation is needed.

${ }^{21}$ The analysis assumes that $N_{s}$ is fixed at the equilibrium level, implicitly assuming that the squatter organizer must agree not to allow any additional migrants into the city. 